\title{
Suppression of Myocardial Inflammation Using Suramin, A Growth Factor Blocker
}

\author{
Takaaki Shiono, MD; Makoto Kodama, MD; Haruo Hanawa, MD; \\ Koichi Fuse, MD; Tadashi Yamamoto, MD*; Yoshifusa Aizawa, MD
}

\begin{abstract}
Autoimmune myocardial injuries are involved in the pathogenesis of myocarditis and dilated cardiomyopathy, but effective strategies for treating myocardial inflammation have not yet been established. The present study investigated the effects of suramin, a growth factor blocker, on experimental autoimmune myocarditis (EAM) in rats. Lewis rats were immunized with cardiac myosin and placed into one of 4 groups: every $72 \mathrm{~h}$ for 1 month the control group (C) was subcutaneously injected with saline; group L received $4 \mathrm{mg} / \mathrm{kg}$ of suramin; group M, 10 $\mathrm{mg} / \mathrm{kg}$; group $\mathrm{H}, 40 \mathrm{mg} / \mathrm{kg}$. The heart weight/body weight ratios of the $\mathrm{M}$ and $\mathrm{H}$ groups were significantly lower than that of the $\mathrm{C}$ group. Macroscopic and microscopic scores for myocarditis were reduced in the $\mathrm{M}$ and $\mathrm{H}$ groups. The expression of transforming growth factor (TGF) $\beta 1 \mathrm{mRNA}$ in the heart was significantly decreased in the $\mathrm{M}$ and $\mathrm{H}$ groups compared with the $\mathrm{C}$. In the next experiment, we investigated the effects of suramin on the cytokine milieu in EAM. The serum level of interleukin-10 on day 15 was significantly increased by suramin treatment. Furthermore, suramin increased the number of T cells with Th2 function in the popliteal lymph nodes. Suramin suppressed myocardial inflammation in EAM and was associated with modulation of the Th1/Th2 cytokine milieu and reduced TGF $\beta 1$ expression in the heart. (Circ J 2002; 66: 385-389)
\end{abstract}

Key Words: Cytokines; Growth factors; Myocarditis; Suramin

$\mathbf{I}$ nflammation and inflammatory substances play a significant role in myocardial damage and it is autoimmune myocardial injuries that are considered to be involved in the pathogenesis of myocarditis and dilated cardiomyopathy!, In order to control autoimmune inflammation, several immunosuppressants have been developed, but these agents have potential hazards: ${ }^{3-5}$ one is systemic adverse effects and another is the permanent use of those agents that is required in order to prevent recurrence. One of the ideal therapeutic strategies for autoimmune inflammation would be promotion of the natural remission process. Suramin is a growth factor blocker with a broad spectrum of action, including transforming growth factor (TGF) $\beta 1$, platelet-derived growth factor (PDGF), vascular endothelial growth factor (VEGF) and basic fibroblast growth factor (bFGF) ${ }^{6,7}$ Suramin is used in anti-parasitic therapy, anti-cancer therapies and suppression of vascular smooth muscle proliferation after injury? One of its unique actions is that it can modulate the Th1/Th2 cytokine balance in inflammation; 9 switching from Th1 polarity to Th2 dominancy is the fundamental natural remission process of various autoimmune diseases $!^{10}$

Experimental autoimmune myocarditis (EAM) in rats is an animal model of human giant cell myocarditis!1 ${ }^{1}$ It can be produced in susceptible animals by immunization with cardiac myosin or by adoptive transfer using T-cells from animals with EAM!2 EAM in Lewis rats has extremely

(Received September 14, 2001; revised manuscript received December 19, 2001; accepted January 9, 2002)

First Department of Internal Medicine and *Department of Pathology, Institute of Nephrology, Niigata University School of Medicine, Niigata, Japan

Mailing address: Takaaki Shiono, MD, First Department of Internal Medicine, Niigata University School of Medicine, 1-754 Asahimachi, Niigata 951-8510, Japan. E-mail: sio@ cocoa.ocn.ne.jp severe pathology and congestive heart failure, so it is suitable for the analysis of the mechanisms of autoimmune myocardial injuries $!^{13}$ The previous results suggest that the initiation and progression of EAM are related to Th1 polarity and remission is associated with Th2 cytokines ${ }^{14}$ Growth factors may also be involved in the pathogenesis of EAM, but have not yet been investigated ${ }^{15}$ We investigated the effects of suramin, a growth factor blocker, on EAM, and also examined the cytokine milieu of EAM.

\section{Methods}

Animals

Male Lewis rats were purchased from Charles River Japan Inc. They were bred and maintained at the Facility for Comparative Medicine and Animal Experimentation, Niigata University School of Medicine.

\section{Antigen and Immunization}

Purified cardiac myosin from the ventricular muscle of pig hearts was prepared according to the procedure previously described ${ }^{11}$ and used as an antigen. Eleven-week-old rats were given a subcutaneous injection of $0.2 \mathrm{ml}$ of antigen-adjuvant emulsion into their footpads on day 0 .

\section{Agent}

Rats with EAM were treated with suramin that used saline as the solvent.

\section{Suramin Treatment}

Rats were placed in one of 4 groups according to the dose of suramin given after the myosin immunization. Group C (control, $\mathrm{n}=7$ ) rats were given a subcutaneous injection of $0.5 \mathrm{ml}$ of saline every $72 \mathrm{~h}$ for 1 month, group $\mathrm{L}$ $(\mathrm{n}=7), 4 \mathrm{mg} / \mathrm{kg}$ suramin, group $\mathrm{M}(\mathrm{n}=7), 10 \mathrm{mg} / \mathrm{kg}$ suramin 


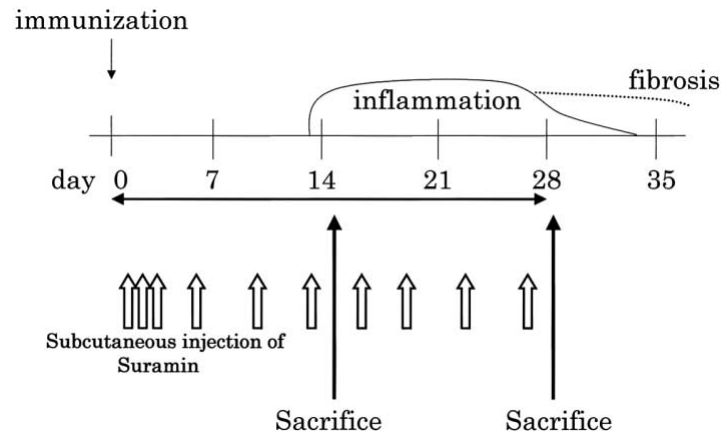

Fig 1. Clinical course of the disease and the experimental schedule.

and group $\mathrm{H}(\mathrm{n}=7), 40 \mathrm{mg} / \mathrm{kg}$ suramin during same period (Fig 1).

\section{Sampling}

Rats were killed under ether anesthesia on day 28 and the macroscopic features of the hearts were graded as $0-2$ according to a classification previously described ${ }^{11}$ Hearts were weighed immediately after the animals were killed. Because the lesions of EAM spread diffusely, precise calculation of the proportion of diseased muscle volume against total muscle mass was difficult. Our observations confirmed that the ratio of heart/body weight best represented the severity of EAM during the acute phase.

\section{Histopathology}

Part of the excised hearts was fixed in $10 \%$ formalin and sliced at several levels to make transverse sections for evaluation. Microscopic findings were graded as $0-3$ in hematoxylin-eosin stained sections according to the classification previously described!1

\section{RNA Extraction and RNase Protection Assay}

The total cellular RNA was purified from the rat hearts

Table 1 Macroscopic and Microscopic Scores of Experimental Autoimmune Myocarditis

\begin{tabular}{lcc}
\hline \hline Group & Macroscopic score & Microscopic score \\
\hline$C$ & $2.0 \pm 0$ & $2.83 \pm 0.41$ \\
$L$ & $2.0 \pm 0$ & $2.80 \pm 0.45$ \\
$M$ & $0.83 \pm 0.75$ & $0.60 \pm 0.55$ \\
$H$ & $0.17 \pm 0.41$ & 0 \\
\hline
\end{tabular}

C, control group; $L, 4 \mathrm{mg} / \mathrm{kg}$ of suramin every $72 \mathrm{~h} ; \mathrm{M}, 10 \mathrm{mg} ; \mathrm{H}, 40 \mathrm{mg}$ $(n=7$ each $)$

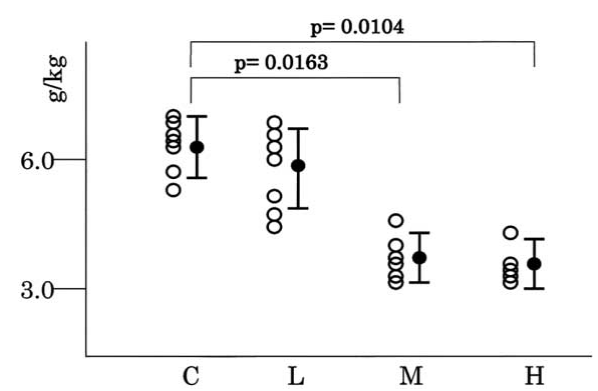

Fig 2. Heart weight/body weight ratio of each group. The value for group C was $6.85 \pm 1.78 \mathrm{~g} / \mathrm{kg}, \mathrm{L}: 6.23 \pm 1.34 \mathrm{~g} / \mathrm{kg}, \mathrm{M}: 3.59 \pm 0.40 \mathrm{~g} / \mathrm{kg}$ and $\mathrm{H}: 3.56 \pm 0.38 \mathrm{~g} / \mathrm{kg}(\mathrm{n}=7$ each). by the acid guanidinium thiocyanate/phenol chorofoform method. Antisense RNA probes incorporated with $\{a-$ ${ }^{32} \mathrm{P}$ \}UTP were prepared by in vitro transcription using the linearized cDNA templates for rat TGF $\beta 1(255 \mathrm{bp})$ and glyceraldehyde phosphate dehydrogenase (GAPDH) (114 bp) with T7 RNA polymerase. The $20 \mu \mathrm{g}$ samples of RNA were hybridized with $1 \times 10^{5}$ counts/min of the ${ }^{32} \mathrm{P}$-labeled antisense RNA probes for TGF $\beta 1$ and GAPDH at $52^{\circ} \mathrm{C}$ for $16 \mathrm{~h}$ as described previously ${ }^{16}$ The autoradiograms were analyzed using an NIH Image 1.59 software program. The expression of TGF $\beta 1 \mathrm{mRNA}$ was presented as a ratio to GAPDH mRNA expression in the sample.

\section{Real-Time Polymerase Chain Reaction (PCR) of Cytokine Genes in the Popliteal Lymph Nodes}

Total cellular RNA was purified from the rats' popliteal lymph nodes and reverse transcription was performed to prepare cDNA samples. Real-time PCR on the LightCycler ${ }^{\circledR}$ (Roche Diagnostics) was performed using DNA Master SYBR Green. Primers for interleukin (IL)-2 were sense, CTGAGAGGGATCGATAATTACAAGA and antisense, ATTGGCACTCAAATTTGTTTTCAG (M22899) and those for IL-10 were sense, ACTGCTATGTTGCCTGCTCTTACT and antisense, GAATTCAAATGCTCCTTGATTTCT (L02926). Samples were quantified by LightCycler Software version $3 ! 7,18$

\section{Quantitation of IL-2 and IL-10 Levels by Enzyme-Linked Immunosorbent Assay (ELISA)}

Serum samples were collected from rats from both suramin treated and non-treated groups that were killed on day 15 . IL-2 and IL-10 were measured by an immunoassay cytokine ELISA kit (Cosmo Bio) according to the manufacturer's instructions ${ }^{14}$

\section{Statistical Analysis}

Data are presented as mean value \pm SEM. The MannWhitney U-test was used to compare difference between
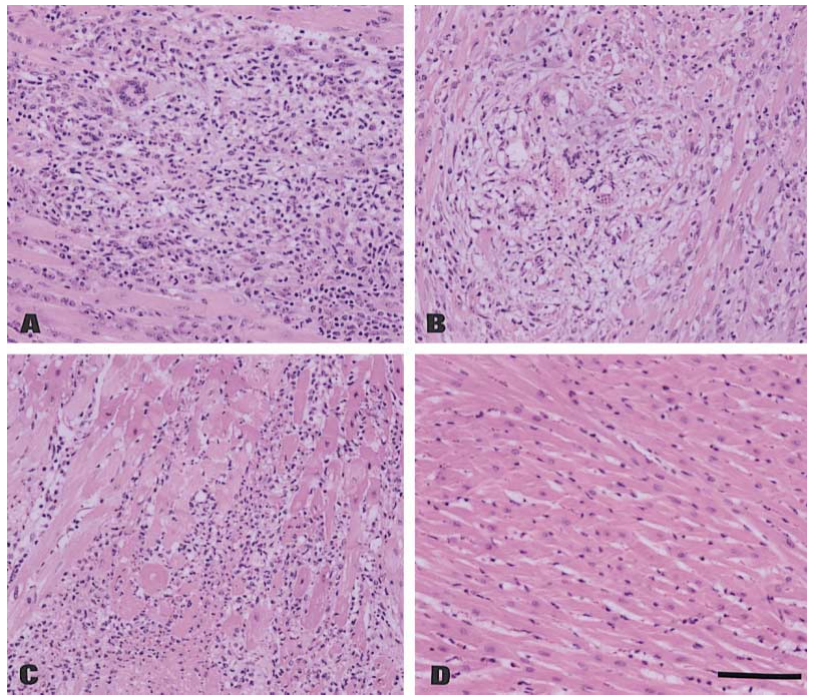

Fig 3. Effects of suramin on histopathological change on day 28 with EAM. (A) Multiple and extensive inflammatory lesions containing giant cells are seen in group C. (B) Severe myocarditis similar to group C is observed in group L. (C) Focal lesions of cellular infiltration are seen in group M. (D) The myocardium of group $\mathrm{H}$ is shown almost intact. $(\mathrm{H} \& \mathrm{E} ; \mathrm{Bar}=100 \mu \mathrm{m})$ 


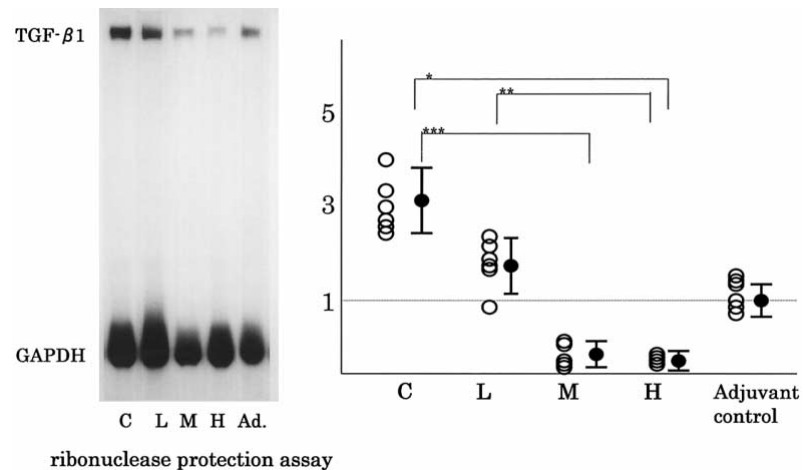

Fig 4. Expression of TGF $\beta 1$ mRNA. The adjuvant group contained rats that were immunized with saline instead of cardiac myosin, so the hearts of this group were normal. Each TGF $\beta 1$ mRNA expression is presented as a ratio to GAPDH mRNA. The mean value of group C was $2.88 \pm 0.49$, L: $1.41 \pm 0.45, \mathrm{M}: 0.096 \pm 0.064, \mathrm{H}: 0.0610 \pm 0.021$ and Adjuvant control: $1.00 \pm 0.51$. The $\mathrm{p}$ values were $* 0.0143$, **0.0209, $* * * 0.0149$.

unpaired samples and $\mathrm{p}<0.05$ was considered significant.

\section{Results}

Clinical Course of Myosin-Immunized Rats

All 7 rats in group $\mathrm{C}$ became ill and immobile in the second week following immunization; 1 rat died on day 16 and another on day 27. All these rats showed macroscopic evidence of severe myocarditis and congestive heart failure at autopsy. None of the rats treated with suramin died spontaneously during the study period.

\section{Macroscopic Findings (Table 1)}

The hearts of the control group and group L were markedly enlarged with large grayish-colored areas on their surface. The hearts of all group $\mathrm{H}$ rats had a normal appearance. The heart weight/body weight ratio of group $\mathrm{C}$ rats was $6.85 \pm 1.78 \mathrm{~g} / \mathrm{kg}$, group L: $6.23 \pm 1.34 \mathrm{~g} / \mathrm{kg}$, group M: $3.59 \pm 0.40 \mathrm{~g} / \mathrm{kg}$ and group H: $3.56 \pm 0.38 \mathrm{~g} / \mathrm{kg}$ (Fig 2). The heart weight/body weight ratio of age-and sex-matched normal Lewis rats was $3.57 \pm 0.39$. The ratios of groups $\mathrm{H}$ and $\mathrm{M}$ were significantly lower than that of the control group.

\section{Microscopic Findings (Table 1)}

Many mononuclear cells had infiltrated the myocardium of rats in the $\mathrm{C}$ and $\mathrm{L}$ groups (Fig 3 ). Inflammatory infiltrates formed clusters at the sites of necrotic myocytes and interstitial edema was evident in both groups. Partial fibrosis was prominent and multinucleated giant cells were frequently observed. The hearts from group $\mathrm{H}$ had few areas of infiltration and fibrosis, and the myocardial damage of group $\mathrm{H}$ was less than that of group C (Fig 3).

\section{TGF $\beta 1$ Gene Expression in the Heart on Day 28}

During the course of EAM, TGF $\beta 1$ gene expression in the heart could be detected and was markedly enhanced on day 21 , after which it gradually diminished. The expression of TGF $\beta 1$ mRNA in the rats treated with a high dose of suramin was significantly lower than in group C (Fig 4).

\section{Serum Levels of Cytokine and Cytokine-Production in Popliteal Lymph Nodes}

In order to evaluate the effects of suramin on cytokine
IL-2 concentration

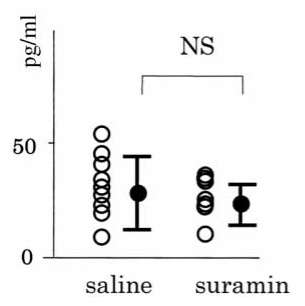

IL-10 concentration

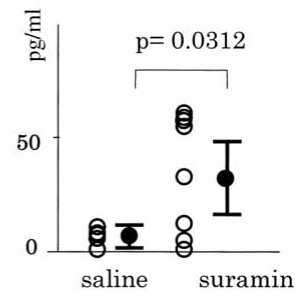

Fig 5. Serum levels of IL-2 and IL-10 on day 15 ( $\mathrm{n}=10$ each).

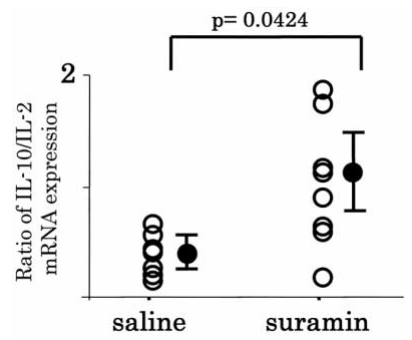

Fig 6. IL-10/IL-2 mRNA expression ratio in the popliteal lymph nodes on day 15 .

production, we set up 2 other groups with EAM. One group was treated with saline and the other group was treated with $40 \mathrm{mg} / \mathrm{kg}$ of suramin for 3 days. The rats were killed on day 15. The heart weight/body weight ratios of the saline-treated and suramin-treated groups were 5.49 \pm 1.46 $\mathrm{g} / \mathrm{kg}$ and $3.80 \pm 0.22 \mathrm{~g} / \mathrm{kg}$, respectively. Induction of EAM was effectively prevented by suramin. The macroscopic scores of the saline-treated and suramin-treated groups were $1.67 \pm 0.58$ and $0.33 \pm 0.58$, respectively.

Serum levels of IL-10 in the $40 \mathrm{mg} / \mathrm{kg}$ suramin treated group were significantly increased on day 15 compared with the saline treated group $(37.9 \pm 32.7 \mathrm{pg} / \mathrm{ml}$ vs $2.99 \pm 4.25$ $\mathrm{pg} / \mathrm{ml}$ ). There was no difference between the suramintreated and saline-treated groups in the serum levels of IL-2 (Fig 5). The pattern of both cytokines messenger RNA expression in the popliteal lymph nodes was similar. The ratio of IL-10/IL-2 mRNA expression was significantly increased in the rats treated with suramin (Fig 6).

\section{Discussion}

This study demonstrated that suramin effectively suppressed EAM and was also able to suppress the expression of TGF $\beta 1 \mathrm{mRNA}$ in the heart of rats with EAM. Various autoimmune diseases may be related to an imbalance between Th1 and Th2 cells; ${ }^{19,20}$ the former secrete IL- 2 and interferon (IFN) $\gamma$ and mediate proinflammatory reactions (termed the Th1 response), whereas the latter secrete IL-4 and IL-10, and promote humoral immunity (termed the Th2 response). Th1 cells suppress the Th2 response through IFN $\gamma$, and IL-10, one of the Th2 cytokines, is a major inhibitor of the Th1 response. Suramin changed the cytokine milieu from predominantly Th1 to Th2 in rats with EAM.

Suramin is a unique agent that acts as a blocker of growth factors and as a cytokine modulator. These actions are different from conventional immunosuppressants or anti-inflammatory agents and may be useful in the therapy of myocarditis and other inflammatory cardiovascular diseases. 
The role of growth factors in the pathogenesis of EAM has not yet been fully clarified ${ }^{2}$ From our preliminary study, mRNA expression of TGF $\beta 1$ increased markedly from day 14 and persisted at a high level over an extended period of time in hearts with EAM. Others have suggested the importance of TGF $\beta 1$ in cardiac remodeling and fibrosis ${ }^{22}$ Some growth factors might be related to the course of organ-specific autoimmune diseases but their function would not be simple ${ }^{23}$ It is postulated that growth factors play a significant role in the healing process after myocardial injury, namely angiogenesis, interstitial matrix formation and myocardial hypertrophy. The present finding that the heart weight/body weight ratio on day 28 was dramatically suppressed by suramin may result from suramin preventing myocardial remodeling by blocking the actions of growth factors. The roles of growth factors in the onset and progression of EAM are still unknown.

On the other hand, cytokines play a major role in the pathogenesis of $\mathrm{EAM}^{22}$ In the hearts with EAM, mRNA expression of IFN $\gamma$, IL-2, IL- $\mathbb{\beta}$ and TNFa increased from the onset of the disease, and subsequently, the mRNA expression of IL-10 could be detected from day 24 and the amount of IL-10 mRNA increased in EAM. Thus, the predominance of either Th1 cytokines or Th2 cytokines is closely related to the disease activity, namely progression or remission. This study demonstrated that suramin produced Th2 dominancy in rats with EAM from day 15 and this switching from Th1 to Th2 dominancy of the cytokine milieu may be the chief mechanism of the suppression of EAM by suramin in this model.

From the results of this study, suramin can prevent the initiation of EAM by modulating the cytokine environment, but cannot improve EAM when administered after the onset of the disease (unpublished observation). The initiation of EAM is considered to be a priming and an activation of cardiac myosin-reactive myocarditogenic CD4 T cells in the lymphatic organs and probably depends on various Th1 cytokines. The subsequent step is a homing of the myocarditogenic $\mathrm{T}$ cells to the heart and this step seems to be controlled by various chemokines and expression of adhesion molecules in the target organ. Once cardiac myosin-reactive myocarditogenic $\mathrm{T}$ cells enter the myocardium, they will be presented with antigen from residential dendritic cells. Reactivation of the primed $\mathrm{T}$ cells rapidly produces a great number of proinflammatory cytokines, which then leads to recruitment of various inflammatory cells, such as lymphocytes, macrophages and neutrophils, in the myocardium. Antigen-specific and nonspecific inflammation of the myocardium both affect myocardial function and lead to myocardial damage. After or coincident with acute inflammation, myocardial remodeling and healing process will begin; the former process may be related to growth factors and the latter may depend on Th2 polarity. The initial process and the priming and activation of myocarditogenic $\mathrm{T}$ cells have been effectively prevented by blocking the carcineurin-pathway of $\mathrm{T}$ cells using cyclosporine or tacrolimus 24,25 Inhibition of inducible nitric oxide synthase (iNOS) production also prevents the progression of inflammation-mediated myocardial damage ${ }^{26}$ As yet there has not been a report of improved myocardial remodeling or promotion of healing in EAM. However, suramin had a unique action in EAM: it could not inhibit Th1 reaction, but it did promote the Th2 reaction in lymphatic organs. Generally, a strong Th1 reaction and severe inflammation of the target organs induce the subse- quent Th2 reaction, but suramin may be able to skip the active inflammatory process in the target organ. Further precise analysis is needed to clarify the role of this unique agent in $\mathrm{T}$ cell activation.

Therapeutic effects of various agents have been investigated in experimental myocarditis. Immunosuppressants are effective for EAM, but are harmful in experimental viral myocarditis. Recently, it was demonstrated that supplementation of IL-10 is effective therapy in animal models of viral myocarditis? ${ }^{27}$ Accordingly, switching from Th1 polarity to Th2 dominancy may become a common therapeutic strategy in myocarditis regardless of its etiology. Until now, there has not been a pharmacological agent that can modulate the Th1/Th2 balance. Suramin is the first agent to possess such a unique action, but its precise actions on lymphocytes need to be clarified.

Growth factors and Th1 cytokines are related to various cardiovascular diseases,22,28 such as chronic heart failure, ischemic myocardial injuries, atherosclerosis of vessels and restenosis after angioplasty. Agents that can block growth factors and modulate the Th1/Th2 balance may open a new field of therapy of cardiovascular diseases.

The effects of suramin on EAM were demonstrated. However, suramin itself has significant nephrotoxicity, so careful investigation is necessary before clinical use. The pharmacological actions of suramin may provide new therapeutic strategies for inflammatory myocardial disorders.

\section{Acknowledgments}

We gratefully acknowledge Mr Nobuhito Takada for his help in our study. We thank the Bayer Co for kindly providing the suramin solution. This study was supported in part by a grant for scientific research from the Ministry of Education, Science and Culture of Japan (No. 10670636).

\section{References}

1. Noel R Rose. Viral damage or 'molecular mimicry': Placing the blame in myocarditis. Nat Med 2000; 6: 631-632.

2. Kawai C. From myocarditis to cardiomyopathy: Mechanisms of inflammation and cell death: Learning from the past for the future. Circulation 1999; 99: 1091-1100.

3. Kodama M, Okura Y, Hirono S, Hanawa H, Ogawa Y, Itoh M, et al. A new scoring system to predict the efficacy of steroid therapy for patients with active myocarditis: A retrospective study. Jpn Circ J 1998; 62: 715-720.

4. Mason JW, O'Connell JB, Herskowitz A, Rose NR, McManus BM, Billingham ME, et al. A clinical trial of immunosuppressive therapy for myocarditis: The Myocarditis Treatment Trial Investigators. $N$ Engl J Med 1995; 333: 269-275.

5. Cooper LT Jr, Berry GJ, Shabetai R. Idiopathic giant-cell myocarditis natural history and treatment: Multicenter Giant Cell Myocarditis Study Group Investigators. N Engl J Med 1997; 336: 1860-1866.

6. Hu Y, Zou Y, Dietrich H, Georg W, Qingbo X. Inhibition of neointima hyperplasia of mouse vein grafts by locally applied suramin. Circulation 1999; 100: 861-868.

7. Waltenberger J, Mayr U, Frank H, Hombach V. Suramin is a potent inhibitor of vascular endothelial growth factor: A contribution to the molecular basis of its antiangiogenic action. J Mol Cell Cardiol 1996; 28: $1523-1529$.

8. Gray TJ, Strauss BH, Hinek A. Inhibitory mechanisms by which suramin may attenuate neointimal formation after balloon angioplasty. J Cardiovasc Pharmacol 1999; 33: 960-971.

9. Novales-Li P. In vitro immunopharmacologic effect of suramin on modifying Th-subset cytokine levels in splenocytes and T-cell clones: A therapeutic application for autoimmune disease. Immunol Lett 1996; 51: 169-173.

10. Seko Y, Takahashi N, Yagita H, Okumura K, Yazaki Y. Expression of cytokine mRNAs in murine hearts with acute myocarditis caused by coxsackievirus b3. J Pathol 1997; 183: 105-108.

11. Kodama M, Matsumoto Y, Fujiwara M, Masani F, Izumi T, Shibata A. A novel experimental model of giant cell myocarditis induced in rats by immunization with cardiac myosin fraction. Clin Immunol 
Immunopathol 1990; 57: 250-262.

12. Kodama M, Matsumoto Y, Fujiwara M. In vivo lymphocyte-mediated myocardial injuries demonstrated by adoptive transfer of experimental autoimmune myocarditis. Circulation 1992; 85: 1918-1926.

13. Stull LB, DiIulio NA, Yu M, McTiernan CF, Ratliff NB, Tuohy VK, et al. Alterations in cardiac function and gene expression during autoimmune myocarditis in mice. J Mol Cell Cardiol 2000; 32: 20352049.

14. Okura Y, Takeda K, Honda S, Hanawa H, Watanabe H, Kodama M, et al. Recombinant murine interleukin-2 facilitates induction of cardiac myosin-specific type 1 helper T cells in rats. Circ Res 1998; 82: $1035-1042$.

15. Flanders KC, Bhandiwad AR, Winokur TS. Transforming growth factor $\beta$ blocks cytokine induction of catalase and xanthine oxidase mRNA levels in cultured rat cardiac cells. J Mol Cell Cardiol 1997; 26: $273-280$.

16. Abe A, Yamamoto T, Isome M, Ma M, Yaoita E, Kawasaki K, et al. Thyroid hormone regulates expression of shaker-related potassium channel mRNA in rat heart. Biochem Biophys Res Commun 1998; 245: $226-230$.

17. Wittwer CT, Ririe KM, Andrew RV, David DA, Gundry RA, Balis UJ. The LightCycler: A microvolume multisample fluorimeter with rapid temperature control. Biotechniques 1997; 22: 176-181.

18. Blaschke V, Reich K, Blaschke S. Rapid quantitation of proinflammatory and chemoattractant cytokine expression in small tissue samples and monocyte-derived dendritic cells: Validation of a new real-time RT-PCR technology. J Immunol Methods 2000; 246: 79-80.

19. Liblau RS, Singer SM, McDevitt HO. Th1 and Th2 CD4+ T cells in the pathogenesis of organ-specific autoimmune diseases. Immunol Today 1995; 16: 34-38.

20. Mosmann TR, Cherwinski H, Bond MW, Giedlin MA, Coffman RL. Two types of murine helper T cell clone. I. Definition according to profiles of lymphokine activities and secreted proteins. J Immunol 1986; 136: 2348-2357.

21. Waltenberger J. Modulation of growth factor action: Implications for the treatment of cardiovascular diseases. Circulation 1997; 96: $4083-$ 4094.

22. Okura Y, Yamamoto T, Goto S, Inomata T, Hirono S, Hanawa H, et al. Characterization of cytokine and iNOS mRNA expression in situ during the course of experimental autoimmune myocarditis in rats. $J$ Mol Cell Cardiol 1997; 29: 491-502.

23. Vinores SA, Chan CC, Vinores MA, Matteson DM, Chen YS, Klein DA, et al. Increased vascular endothelial growth factor (VEGF) and transforming growth factor beta (TGFbeta) in experimental autoimmune uveoretinitis: Upregulation of VEGF without neovascularization. J Neuroimmunol 1998; 89: 43-50.

24. Zhang S, Kodama M, Hanawa H, Izumi T, Shibata A, Masani F. Effects of cyclosporine, predonisolone and aspirin on rat autoimmune giant cell myocarditis. J Am Coll Cardiol 1993; 21: 1254-1260.

25. Hanawa H, Kodama M, Zhang S, Izumi T, Shibata A. An immunosuppressant compound, FK-506, prevents the progression of autoimmune myocarditis in rats. Clin Immunol Immunopathol 1992; 62: $321-326$.

26. Hirono S, Islam MO, Nakazawa M, Yoshida Y, Kodama M, Shibata A, et al. Expression of inducible nitric oxide synthase in rat experimental autoimmune myocarditis with special reference to changes in cardiac hemodynamics. Circ Res 1997; 80: 11-20.

27. Nishio R, Matsumori A, Shioi T, Ishida H, Sasayama S. Treatment of experimental viral myocarditis with interleukin-10. Circulation 1999; 100: $1102-1108$.

28. Fuse K, Kodama M, Okura Y, Ito M, Aoki Y, Hirono S, et al. Levels of serum interleukin-10 reflect disease activity in patients with cardiac sarcoidosis. Jpn Circ J 2000; 64: 755-759. 